\section{OBTAINING ADEQUATE SURGICAL MARGIN STATUS IN BREAST-CONSERVATION THERAPY: INTRAOPERATIVE ULTRASOUND-GUIDED RESECTION VERSUS SPECIMEN MAMMOGRAPHY}

\section{MARIA MIHAELA POP ${ }^{1}$, SILVIU CRISTIAN ${ }^{1}$, ORSOLYA HANKO-BAUER ${ }^{2}$, DANA VALENTINA GHIGA ${ }^{3}$, RARES GEORGESC ${ }^{2}$}

\author{
${ }^{1}$ General Medicine, University of Medicine and Pharmacy of Tîrgu Mureș, \\ Romania \\ ${ }^{2}$ Department of Surgery, University of Medicine and Pharmacy of Tîrgu Mureș, \\ Romania \\ ${ }^{3}$ Department of Research Methodology, University of Medicine and Pharmacy of \\ Tîrgu Mureș, Romania
}

\section{Abstract}

Background and aim. The purpose of breast-conserving surgery (BCS) for women with cancer is to perform an oncological radical procedure with disease-free margins at the final histological assessment and with the best aesthetic result possible. Intraoperative resected specimen ultrasound and intraoperative resected specimen mammography may reduce the rates of positive margins and reexcision among patients undergoing conserving therapy. Our objective is to compare the two methods with the histopathological results for a preset cut off and asses which parameters can influence the positive margin status.

Method. A prospective study was performed on 83 patients who underwent breast conservation surgery for early breast cancer (pT1-3a pN0-1 M0) between 2014 and 2016. After excision the specimen was oriented in the operating room by the surgeon. Metallic clips and threads were placed on margins: one clip and the long thread at $12 \mathrm{o}$ 'clock, two clips and the short threads at 9 o'clock. The next step was intraoperative ultrasound assessment of the specimen. For the margins under $2 \mathrm{~mm}$ we performed selective margin shaving, followed by mammography to identify and document the lesion and finally histopathological examination of the specimen with reporting the gross and microscopic margins. The positive margins required re-excision or boost of radiation at the posterior or anterior margins, depending on the case.

Results. We set a cut-off at $2 \mathrm{~mm}$. The sensitivity and specificity of the intraoperative margin assessment via the ultrasound method were 90.91\% (95\% CI 70.84-98.88\%) and $67.21 \%$ (95\% CI 54-78.69\%) respectively. The sensitivity and specificity of the intraoperative margin assessment via the mammographic procedure were $45.45 \%$ (95\% CI 24.39-67.79\%) and $85.25 \%$ (95\% CI 73.83-93.02\%) respectively. There was positive correlation between the histopathological and intraoperative ultrasound exam $(p=0.018)$ and negative correlation between the histopathological exam and the post-operative mammographic exam $(p=0.68)$. We found a positive correlation between the positive margin status and age $(<40)$, preoperative chemotherapy, intraductal carcinoma, inflammatory process around the tumor, and the immunohistochemical triple negative profile.

Conclusions. According to our results, the intraoperative ultrasound of the breast specimen for a cutt-off at $2 \mathrm{~mm}$ can decrease the rates of margin positivity compared to the mammographic procedure and has the potential to diminish the number of subsequent undesired re-excisions.

Keywords: breast-conserving surgery, intraoperative ultrasound, specimen mammography 


\section{Background and aims}

Surgery continues to be the main pillar of breast cancer therapy nowadays. With the development and widespread of breast cancer diagnostic techniques, the addition of adjuvant therapy, the expansion of knowledge in the field of cancer biology have led in recent decades to the narrowing of the operative act and the emergence of a new concept: conservative surgery. As an alternative to mastectomy, conservative surgery pursues two goals: effective local oncology (radicality) and achieving the best aesthetic result possible, with the main focus being on the principle of radicalism $[1,2]$. Surgical treatment for early stage breast cancer hasn't always been breast conservative. In 1894 William Halsted revolutionized his time with the radical mastectomy. Half a century later, in 1948 Patey and Madden refined the procedure, introducing the modified radical mastectomy $[3,4,5]$. Medicine evolved and paradigms shifted, making breast conservation therapy the desired technique after the 1991 National Institute of Health Consensus on breast cancer, determined by the Veronessi and Fisher studies, a few years earlier $[6,7,8]$.

The goal for patients with early breast cancer is to obtain negative margins at the final histological assessment $[9,10]$. Among the first trials to deal with this matter were the ones published by Gustave Roussy Institute (1988), Stanford University Medical Center (1972-1992) and START trial (1992-2002) [11,12,13]. The 2014 guidelines endorsed by SSO-ASTRO Consensus, advocate no ink on tumor as the new margin requirement. This approach to breast cancer has gained rapid followers around the world, being today a commonly recognized treatment method [14].

The current intra-operative trend is the simultaneous use of diagnostic and therapeutic procedures, resulting in the so-called "theranostic" procedure in which intraoperative ultrasonography plays an important role in assessing marginal status and having the ability to differentiate normal tissue from benign or malignant changes $[15,16,17]$. In 1988, Schwartz published a study using ultrasound as an alternative technique for detecting non-palpable breast tumors $[18,19]$. Since then, other studies have sought to confirm the feasibility and safety of the impalpable and palpable breast tumor method [20-24]. Another approach designed to achieve negative margins is mammography of the specimen. The accuracy of the method is determined by its ability to provide information on the presence or absence of microcalcifications, but also on parenchymal distortions $[25,26,27]$. Among the limitations of this technique are the "pancake" phenomenon and the existence of an invasive lobular carcinoma surrounded by dense tissue. The latter requires, according to the 2005 Consensus Statement issued by the American Society of Breast Surgeons, the use of MRI over mammography $[28,29]$.

The main aim of the study is the evaluation of intraoperative ultrasonography and mammography of the specimen excised according to the final result of the histopathological examination in order to obtain a negative margin status for a preset cut-off. The secondary objective is to determine the parameters that can influence margin status.

\section{Methods}

Eligibility. An observational prospective study was performed on 83 patients who underwent breast conservation surgery (BCS) for early breast cancer (pT1-3a pN0-1 M0) between 2014 and 2016 in Tîrgu Mureş County Hospital, Department of General Surgery. The study was approved by the Ethics Committees of the Tîrgu Mureș County Hospital and of the University of Medicine and Pharmacy of Tîrgu Mureş. Pregnant women, patients with benign pathology at final histopathological assessment, patients unable to receive anesthesia or those refusing surgical treatment, were excluded.

Clinical Protocol. During the operation, after excision, the specimen was oriented in the operating room by the surgeon. Metallic clips and threads were placed on the margins: one clip and the long thread at 12 o'clock, two clips and the short threads at 9 o'clock. The next step was intraoperative ultrasound assessment of the specimen, using Philips ClearVue 650 with the frequency linear transducer set at $12 \mathrm{MHz}$. The procedure was performed directly on the specimen after resection, without prior immersion of the surgical piece in saline solution. Selective margin shavings were carried out for close margins $(<2 \mathrm{~mm})$ at the discretion of the surgeon and the new margins of the additional resections were oriented by sutures. Afterwards intraoperative resected specimen mammography was performed, and six radial distances from all margins (superior, inferior, lateral, medial, anterior and posterior) were recorded to identify and document the targeted lesion. Finally, the specimens were evaluated by board certified pathologists who painted the six surfaces and reported the gross and microscopic margins. The new resection margins of the additional intraoperative resections were also inked. The tissue specimen and additional resections were serially sectioned at 3- to 3-mm intervals and stained by hematoxylin and eosin. Reoperation was recommended for any margin $<2 \mathrm{~mm}$ at the pathology assessment.

Statistical analysis. The analysis was made on the number of patients on whom the methods demonstrated evidence of tumor cells at least one resection margin or very close to a margin $(<2 \mathrm{~mm})$. Subsequently the data was processed using Microsoft Office Excel 2010 tables. Calculation of sensitivity and specificity were performed using MedCalc 17.4.4. The results were further compiled using the GraphPad Prism 6 program. The correlation of the different parameters required the application of tests such as: test $\mathrm{T}$ student for non-paired data, Fisher test, Chi square test. $\mathrm{P}$ values $<0.05$ were considered statistically significant. 


\section{Results}

The study group included 83 patients aged between 33-89 years with the median age of 57.3. They were divided into 2 age subgroups: $<40$ years $(\mathrm{n}=10), \geq 40$ years $(\mathrm{n}=73) .74(89 \%)$ patients had a tumor-free margin. Of note, a tumor-free margin was defined as 'no tumor on ink'. Specimen ultrasound (hypoechoic targeted mass found $<2$ $\mathrm{mm}$ from the edge) had a sensitivity of $90.91 \%$ ( $95 \% \mathrm{CI}$

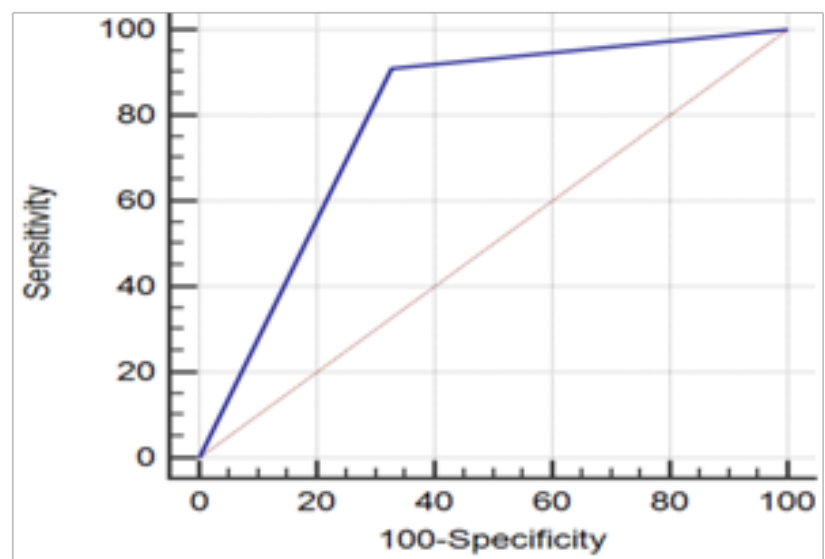

Figure 1. ROC Curve regarding the comparison of specimen ultrasound margins with surgical pathology $2 \mathrm{~mm}$ cut-off.
70.84-98.88\%) and specificity of $67.21 \%$ (95\% CI 54$78.69 \%$ ) in the evaluation of surgical pathology margins (Figure 1, Table I). Regarding the specimen mammography margins with $2 \mathrm{~mm}$ cut-off, the sensibility and specificity were $45.45 \%$ (95\% CI $24.39-67.79 \%$ ) respectively $85.25 \%$ (95\% CI 73.83-93.02\%) (Figure 2, Table II).

The correlation between different parameters and the marginal status is exemplified in Table III.

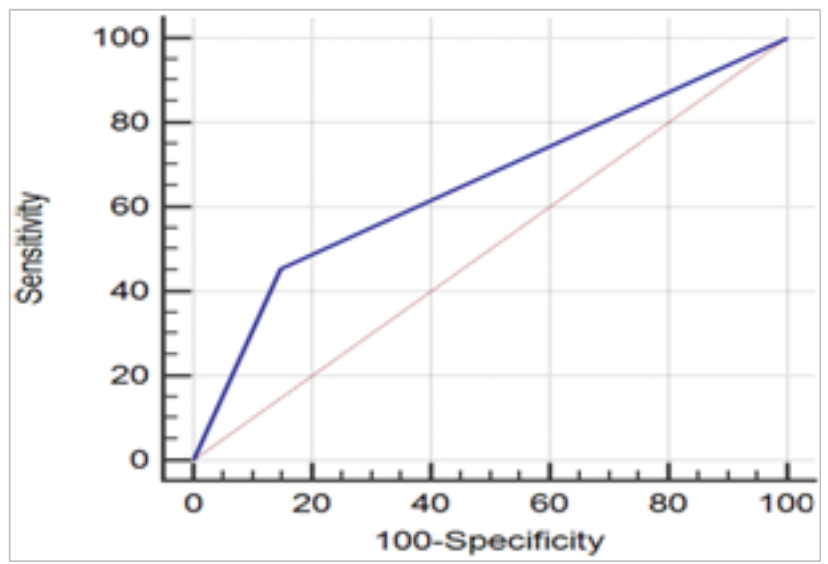

Figure 2. ROC Curve regarding the comparison of specimen mammography margins with surgical pathology $2 \mathrm{~mm}$ cut off.

Table I. Comparison of specimen ultrasound margins with surgical pathology (cut off=2 mm).

\begin{tabular}{llll}
\hline Specimen ultrasound & Surgical pathology positive & Margins report negative & Total \\
\hline Positive $(<2 \mathrm{~mm})$ & 8 (true positive) & 25 (false positive) & 33 \\
\hline Negative $(>2 \mathrm{~mm})$ & 1 (false negative) & 49 (true negative) & 50 \\
\hline Total & 9 & 74 & 83 \\
\hline
\end{tabular}

Table II. Comparison of specimen mammography margins with surgical pathology (cut off=2 mm).

\begin{tabular}{llll}
\hline Specimen mammography & Surgical pathology positive & Margins report negative & Total \\
\hline Positive $(<2 \mathrm{~mm})$ & 4 (true positive) & 11 (false positive) & 15 \\
\hline Negative $(>2 \mathrm{~mm})$ & 5 (false negative) & 63 (true negative) & 68 \\
\hline Total & 9 & 74 & 83 \\
\hline
\end{tabular}

Table III. The correlation between different parameters and the surgical margin status.

\begin{tabular}{|c|c|c|}
\hline Variable & Applied Test & P value \\
\hline Age: $<40$ or $\geq 40$ & \multirow{2}{*}{ Unpaired $\mathrm{T}$ test } & $\mathrm{P}<0.01$ \\
\hline Tumor size $<20 \mathrm{~mm}$ or $>20 \mathrm{~mm}$ & & $\mathrm{P}=0.965$ \\
\hline Preoperative chemotherapy: Yes/ No & \multirow{2}{*}{ Fisher test } & $\mathrm{P}=0.0302$ \\
\hline Histologic type: Ductal/lobular/others & & $\mathrm{P}=0.0406$ \\
\hline Grade: $1 / 2 / 3$ & \multirow{8}{*}{ Chi Square test } & $\mathrm{P}=0.144$ \\
\hline Microcalcifications: Present/Absent & & $\mathrm{P}=0.135$ \\
\hline Necrosis factor: Present/Absent & & $\mathrm{P}=0.967$ \\
\hline Vascular emboli: Present/Absent & & $\mathrm{P}=0.6968$ \\
\hline Inflammatory infiltrate: Present/Absent & & $\mathrm{P}=0.015$ \\
\hline Multifocal tumor: Yes/No & & $\mathrm{P}=0.4474$ \\
\hline $\begin{array}{l}\text { Immunohistochemical profile: Luminal B-Her2 } \\
\text { negative/A/Triple negative }\end{array}$ & & $\mathrm{P}=0.0106$ \\
\hline N-stage: N0/N1 & & $\mathrm{P}=0.5759$ \\
\hline
\end{tabular}




\section{Discussion}

The evaluation of the final histopathological result in BCS occupies a particularly important place in the current literature, which is why we considered it necessary to compare the results obtained in the present study with other clinical trials.

The MAIN OBJECTIVE was the correlation between the final interpretation of the histopathological exam with intraoperative ultrasound, respectively mammogram of the excised specimen. In recent years, numerous studies have evaluated various techniques of obtaining negative histopathological margins, and the two methods currently constitute, according to the literature, techniques with a fairly high accuracy in the assessment of margin status.

\section{Intraoperative ultrasonography}

For a $2 \mathrm{~mm}$ cut-off, our study results showed a sensitivity of $90.91 \%$, a specificity of $67.21 \%$ and a $p$ value $=0.018$. The re-excision rate in a second, postoperative time was $9 \%$ ( 1 case) while the primary reexcision rate for at least one excised specimen margin was 30\% (25 cases).

Various studies are available in the literature to evaluate intraoperative ultrasonography, whose values are close to those obtained in our study. Of these, it is worth mentioning the study by Scaranelo A.M. in which the sensitivity of the method was $100 \%$ and the specificity $59 \%$, the study by Eichler C. in which resection was achieved in $96.4 \%$ (81) patients in the ultrasound group compared to $82.5 \%$ (137) in the control group. Another study conduced by Karanlik $\mathrm{H}$ obtained adequate resection on $94 \%$ of patients in the US-guided surgery group and on $83 \%$ of patients in the palpation guided group $(\mathrm{p}=0.03)$. However, Olsha $\mathrm{O}$. et al in a study on 45 patients conclude that intraoperative ultrasonography tends to overestimate the real margin width, reporting the sensitivity and specificity equal with $25 \%$ and $95 \%$, respectively [22,23,30,31].

\section{Specimen mammography}

For a $2 \mathrm{~mm}$ cut-off the results of our study showed a sensitivity of $45.45 \%$, a specificity of $85.25 \%$ and $p$ value of 0.18 . The re- excision rate in a second operating time would have been $6 \%$ ( 5 cases) while the primary reexcision rate for at least one margin of the excised specimen was $15 \%$ (11 cases).

Various studies are available in the literature to evaluate the mammography of the excised specimen, whose values are close to those obtained in the present study. Among them we mention the study of Bathla L et al. in which the sensitivity of the method was $20.6 \%$ and the specificity $94.6 \%$, the study by Hisada $\mathrm{T}$ et al. in which the sensitivity of the method was $58.5 \%$ and the specificity of $91.8 \%$, the study by McCormick TJ et al. in which sensitivity was $54.55 \%$, and the specificity was $87.80 \%[25,26,27]$

\section{Intraoperative ultrasonography versus specimen mammography}

Further, comparing the results obtained for a 2 $\mathrm{mm}$ cut-off between intraoperative ultrasonography and excised specimen mammography, a higher accuracy of the first method in margin status assessment (90\%) is shown with a re-excision rate in the secondary operating time of $9 \%$. Devolli D et al. in a study of 546 patients showed the superiority of ultrasonography with predilection in young and dense breasts. Another study by Lehman CD and collaborators on a group of 954 patients supports the results of our study, in their case the sensitivity in ultrasonography being $95.7 \%$ compared to $60.9 \%$ in mammography $[24,32]$.

The SECOND OBJECTIVE of the study was the evaluation of the various parameters in relation to the positive margin status.

Thus, correlating the age groups with the final histopathological results in a statistically significant association $(p<0.01)$ due to the dense breast tissue consistency and negative ER for the under 40-year-old group. Similar results have been reported in other studies such as those published by Devolli D, Scaranelo AM, Jobsen JJ and Vrieling C [23,24,33,34].

The use of preoperative chemotherapy is also statistically associated with the histopathological outcome $(p=0.0302)$ because the reduction in tumor volume following adjuvant therapy is not always concentric, making it more difficult to obtain free tumor margins $[29,35]$.

Regarding the histological type, the values obtained from the study showed a statistically significant association between the presence of intraductal carcinoma or combined with intralobular carcinoma and marginal positive status $(p=0.04069)$ due to the type of extension that characterizes this tissue. This is consistent with similar studies which showed the impact of the aforementioned parameter on the marginal status $[15,23,29,36]$.

The presence of inflammatory infiltrate in the tumor bed correlates with the marginal positive status $(\mathrm{p}=0.015)$ because ultrasounds are pulsed rather than transmitted continuously. This causes a less precise delimitation between malignant and healthy tissue.

A substantial part of the literature links some subtypes of the immunohistochemical profile with the marginal positive status and a high rate of recurrence $[14,29,35]$. In the present paper, the triple negative profile statistically changes the histopathological end result $(p=0.0106)$ due to the aggressive character and the presence of the intraductal component.

In terms of tumor size, tumor degree, presence of microcalcifications, necrosis factor, vascular embolisms, multifocal tumors and tumor infiltrating lymph nodes, a statistically significant association with the marginal positive status was not found, although some of these parameters influence the histopathological outcome $[3,29,33,35,36]$. The explanation would be that, in terms of tumor size, $67.5 \%$ of patients have tumors below $2 \mathrm{~mm} ; 1.2 \%$ have grade 3 and the rest grade 1 and 2; Although $43.3 \%$ of the patients had microcalcifications, only $13.8 \%$ had marginal 
positive status. According to the results, a small number of patients had necrosis and vascular emboli at tumor bed: $21.6 \%$ and $27.7 \%$,respectively. Considering the presence of multifocal tumors (10.84\%) and tumor infiltrating lymph nodes $(27.7 \%)$, there was also no statistical correlation with the histopathological outcome.

Clearly, our study had some limitations. Among these, the small number of cases included in the study group compared to other studies addressing the same subject, as well as the impossibility to perform mammography of the excised intraoperative specimen, that would probably have brought to light certain changes in the tumor bed, which ultrasonography is not capable of assessing with the same accuracy.

\section{Conclusions}

In the study of 83 patients, diagnosed with earlystage breast cancer (pT1-3a pN0-1 M0), subjected to surgical treatment at the Department of Surgery 1, Mureş County Clinical Hospital from January 2014 to December 2016, the following were demonstrated:

- Intraoperative ultrasonography is superior to mammography of the excised specimen for a $2 \mathrm{~mm}$ cut-off, being a safe, fast, cheap, radiation-free method with a fairly high availability in any health care center.

- Concerning the cut-off that we should consider in ultrasonography, our study proves the $2 \mathrm{~mm}$ cut-off is more appropriate considering that we are talking about a surgical technique that attempts to preserve the breast.

- Excision specimen mammography is an adjuvant method of ultrasonography due to a higher precision in cases where parenchymal microcalcifications and distortions are present.

- According to our study, particular attention should be paid to the under 40 years of age group, to those who have undergone preoperative chemotherapy, to patients with intraductal and inflammatory infiltrate component at percutaneous biopsy and the triple negative immunohistochemical subtype.

\section{References}

1. Coroș MF, Cozma D, Crăciun C, Georgescu R. General surgery vol II. Ed. University Press. 2015, pp 220-221, 232-241.

2. Newman LA, Washington TA. New trends in breast conservation therapy. Surg Clin North Am. 2003;83:841-883.

3. Brunicardi CF, Andersen DK, Billiar TR, Dunn DL, Hunter JG, et al. Schwartz's principles of surgery tenth edition. Ed. McGrawHill Education. 2015, pp 17, 497-499, 537-548.

4. De Moulin D. A short history of breast cancer. Ed. Kluwer Academic Publishers. 1989, pp 1-9, 17-30.

5. Halsted WS. I. The Results of Operations for the Cure of Cancer of the Breast Performed at the Johns Hopkins Hospital from June, 1889, to January, 1894. Ann Surg. 1894;20:497-555.

6. Mohsin SK. Frozen section library: breast. Ed. Springer. 2012;2:33-34.

7. Fisher B, Jeong JH, Anderson S, Bryant J, Fisher ER, Wolmark
N. Twenty-five-year follow-up of a randomized trial comparing radical mastectomy, total mastectomy, and total mastectomy followed by irradiation. N Engl J Med. 2002;347(8):567-575.

8. Veronesi U, Cascinelli N, Mariani L, Greco M, Saccozzi R, Luini A, et al. Twenty-year follow-up of a randomized study comparing breast-conserving surgery with radical mastectomy for early breast cancer. N Engl J Med. 2002;347(16):1227-1232.

9. Houssami N, Macaskill P, Marinovich ML, Dixon JM, Irwig L, Brennan ME, et al. Meta-analysis of the impact of surgical margins on local recurrence in women with early-stage invasive breast cancer treated with breast-conserving therapy. Eur J Cancer. 2010;46:3219-3232.

10. Smitt MC, Nowels K, Carlson RW, Jeffrey SS. Predictors of reexcision findings and recurrence after breast conservation. Int $\mathrm{J}$ Radiat Oncol Biol Phys. 2003;57:979-985.

11. Sarrazin D, Arriagada R, Contesso G, Fontaine F, Spielmann $\mathrm{M}$, et al. Ten-year results of a randomized trial comparing a conservative treatment to mastectomy in early breast cancer. Elsevier Science Publishers B.V. 1989;14:177-184.

12. Smitt MC, Nowels KW, Zdeblick MJ, Jeffrey S, Carlson RW, Stockdale FE, et al. The importance of the lumpectomy surgical margin status in long-term results of breast conservation. Cancer. 1995;76(2):259-267.

13. START Trialists' Group, Bentzen SM, Agrawal RK, Aird EG, Barrett JM, Barrett-Lee PJ et al. The UK Standardisation of Breast Radiotherapy (START) Trial A of radiotherapy hypofractionation for treatment of early breast cancer: a randomised trial. Lancet Oncol. 2008;9:331-341.

14. Moran MS, Schnitt SJ, Giuliano AE, Harris JR, Khan SA, Horton J, et al. Society of Surgical Oncology-American Society for Radiation Oncology consensus guideline on margins for breast-conserving surgery with whole-breast irradiation in stage I and II invasive breast cancer. Int J Radiat Oncol Biol Phys. 2014;88(3):553-564.

15. Pleijhuis RG, Graafland M, de Vries J, Bart J, de Jong JS, van Dam GM. Obtaining adequate surgical margins in breastconserving therapy for patients with early-stage breast cancer: current modalities and future directions. Ann Surg Oncol. 2009; 16:2717-2730.

16. Mamou J, Oelze ML, O'Brien WD Jr, Zachary JF. Extended three-dimensional impedance map methods for identifying ultrasonic scattering sites. J Acoust Soc Am. 2008;123:11951208.

17. Li C, Duric N, Huang L. Breast imaging using transmission ultrasound: reconstructing tissue parameters of sound speed and attenuation in 2008 International Conference on BioMedical Engineering and Informatics: 27-30 May 2008, Sanya, China. Peng Y, Zhang. 2008;708-712.

18. Schwartz GF, Goldberg BB, Rifkin MD, D'Orazio SE. Ultrasonography: an alternative to $x$-ray-guided needle localization of nonpalpable breast masses. Surgery. 1988;104:870-873.

19. Rahusen FD, Bremers AJ, Fabry HF, Taets van Amerongen AH, Boom RP, Meijer S. Ultrasound-guided lumpectomy of nonpalpable breast cancer versus wire-guided resection: a randomized clinical trial. Ann Surg Oncol. 2002;9:994-998.

20. Davis KM, Hsu CH, Bouton ME, Wilhelmson KL, Komenaka IK. Intraoperative ultrasound can decrease the re-excision lumpectomy rate in patients with palpable breast cancers. Am Surg. 2011;77:720-725.

21. Fisher CS, Mushawah FA, Cyr AE, Gao F, Margenthaler JA. Ultrasound-guided lumpectomy for palpable breast cancers. Ann 
Surg Oncol. 2011;18:3198-3203.

22. Olsha O, Shemesh D, Carmon M, Sibirsky O, Abu Dalo R, Rivkin L, et al. Resection margins in ultrasound-guided breastconserving surgery. Ann Surg Oncol. 2011;18:447-452.

23. Scaranelo AM, Moshonov H, Escallon J. A prospective pilot study of analysis of surgical margins of breast cancers using highresolution sonography. Springerplus. 2016 Mar 1;5:251. doi: 10.1186/s40064-016-1921-2.

24. Devolli-Disha E, Manxhuka-Kërliu S, Ymeri H, Kutllovci A. Comparative accuracy of mammography and ultrasound in women with breast symptoms according to age and breast density. Bosn J Basic Med Sci. 2009;9(2):131-136.

25. McCormick JT, Keleher AJ, Tikhomirov VB, Budway RJ, Caushaj PF. Analysis of the use of specimen mammography in breast conservation therapy. Am J Surg. 2004;188:433-436.

26. Bathla L, Harris A, Davey M, Sharma P, Silva E. High resolution intra-operative two-dimensional specimen mammography and its impact on second operation for re-excision of positive margins at final pathology after breast conservation surgery. Am J Surg. 2011;202:387-394.

27. Hisada T, Sawaki M, Ishiguro J, Adachi Y, Kotani H, Yoshimura A, et al. Impact of intraoperative specimen mammography on margins in breast-conserving surgery. Mol Clin Oncol. 2016;5:269-272.

28. Graham RA, Homer MJ, Katz J, Rothschild J, Safaii H, Supran S. The pancake phenomenon contributes to the inaccuracy of margin assessment in patients with breast cancer. Am J Surg. 2002;184:89-93.

29. O'Sullivan JM, Morrow M, Dirbas FM et al. Breast surgical techniques and interdisciplinary management. Springer 2011, pp 32, 373-81.

30. Eichler C, Hübbel A, Zarghooni V, Thomas A, Gluz O, Stoff-Khalili M, Warm M. Intraoperative ultrasound: improved resection rates in breast-conserving surgery. Anticancer Res. 2012;32:1051-1056.

31. Karanlik H, Ozgur I, Sahin D, Fayda M, Onder S, Yavuz E. Intraoperative ultrasound reduces the need for re-excision in breast-conserving surgery. World J Surg Oncol. 2015 Nov 24;13:321. doi: 10.1186/s12957-015-0731-2.

32. Lehman CD, Lee CI, Loving VA, Portillo MS, Peacock S, DeMartini WB. Accuracy and value of breast ultrasound for primary imaging evaluation of symptomatic women 30-39 years of age. AJR Am J Roentgenol. 2012;199(5):1169-1177.

33. Jobsen JJ, Van Der Palen J, Ong F, Meerwaldt JH. Differences in outcome for positive margins in a large cohort of breast cancer patients treated with breast-conserving therapy. Acta Oncol. 2007;46:172-180.

34. Vrieling C, Collette L, Fourquet A, Hoogenraad WJ, Horiot JC, Jager JJ, et al. Can patient-, treatment- and pathology-related characteristics explain the high local recurrence rate following breast-conserving therapy in young patients? Eur J Cancer. 2003;39:932-944.

35. Harris JR, Lippman ME, Morrow M, Kent Osborne C. Diseases of the breast. Wolter Kluwer 2014, pp 35, 514-536.

36. Kurniawan ED, Wong MH, Windle I, Rose A, Mou A, Buchanan M, et al. Predictors of surgical margin status in breastconserving surgery within a breast screening program. Ann Surg Oncol. 2008;15:2542-2549. 